\title{
REPORT ON DRUG ADDICTION
}

\author{
REPRINTED FROM THE \\ BulLETIN OF THE NEW YORK ACADEMY OF MEDICINE \\ $1955 ; 31(8): 592-607$ \\ THE NEW YORK ACADEMY OF MEDICINE* \\ COMMITTEE ON PUBLIC HEALTH† \\ SUBCOMMITTEE ONDRUG ADDICTIONF
}

\begin{abstract}
Under date of January 14, 1955, there was presented to the Senate of the United States by Senator Frederick G. Payne, Republican, of Maine, a joint resolution "to provide for a more effective control of narcotic drugs, and for other purposes." Co-sponsoring the Resolution with Senator Payne were forty-two other Senators from all areas of the Nation and from all political parties, including Independent Senator Wayne Morse of Oregon.

The Interdepartmental Committee consisting of representatives from the Department of State, Department of the Treasury, Department of Defense, Department of Health, Education and Welfare, and the Department of Justice requested the Committee on Public Health of The New York Academy of Medicine to study this bill and submit a report. By the time the Subcommittee on Drug Addiction of the Committee on Public Health had an opportunity to convene it was informed that the narcotics bill had not come out of committee. However, representatives of the Interdepartmental Committee requested that the Committee on Public Health consider the narcotics problem and propose measures for suitable legislation.

Today a number of cities are raising a hue and cry of apprehension and alarm over drug addiction. Charges and claims about it appear in the headlines, coupled with demands for action of the usual kind: crackdown by the enforcement officials. Presently it is linked with the larger problem of juvenile delinquency as one of its most serious components. Before attempting to appraise the existing situation, it is helpful to look at the legal provisions and administrative bodies designed to control narcotic traffic and addiction.
\end{abstract}

*Approved by Edward J. Donovan, M.D., President, The New York Academy of Medicine, June 7, 1955.

tApproved by the Committee on Public Health of The New York Academy of Medicine, June 6, 1955.

†Report prepared by Subcommittee on Drug Addiction, comprised of: Hubert S. Howe, M.D., Chairman; Linn J. Boyd, M.D.; McKeen Cattell, M.D.; Milton J. Goodfriend, M.D.; Arthur Vose Greeley, M.D.; Lawrence C. Kolb, M.D.; Asa L. Lincoln, M.D.; Bernard J. Pisani, M.D.; Dickinson W. Richards, M.D.; Conrad M. Riley, M.D.; H. D. Kruse, M.D.; Secretary. 


\section{LAWS AND ADMINISTRATION}

\section{INTERNATIONAL BACKGROUND}

At the instance of the United States Government, the conference of the International Opium Commission convened in Shanghai in 1909 in an effort to obtain international action to control the traffic in opium and its products. The Commission recommended that drastic measures be taken by each government in its own territories to control the manufacture, sale and distribution of opium derivatives. Three years later the representatives of twelve world powers met at The Hague to formulate the recommendations of the Commission into an international convention. Here was reached the first important international agreement on the subject, which is known formally as the International Opium Convention of 1912, and popularly as the Hague Convention of 1912. This Convention was designed to bring about the gradual suppression of the abuse of opium, its products and derivatives, and cocaine. The signatory powers contracted to enact effective laws, or regulations, for the control of the production and distribution of raw opium; for prevention of export of raw opium to countries which shall have prohibited its entry; for control of the export of raw opium to countries which restrict its import; and for restricting both import and export of raw opium to that made by duly authorized persons. They further agreed to take measures for the gradual and effective suppression of the manufacture, distribution and use of prepared opium. They also engaged to exert efforts to restrict the import and export of morphine and cocaine preparations to authorized persons and to limit the manufacture, sale and use of these drugs exclusively for medical and scientific purposes.

\section{Federal Background}

Congress has no power to legislate for the mere purpose of restraining the purchase of opiates and other drugs. Rather, its power to enact Federal legislation regulating all phases of the production, manufacture, sale and use of narcotic drugs derives from the commerce clause and the tax clause of the United States Constitution. Under the commerce power, it may forbid the importation of drugs and make the violation of the statute a criminal offense. Under its taxing power it has been held that Congress may prohibit all purchase or sale of narcotics except in or from the original stamped package.

On these constitutional bases, Federal legislation effectuating the Convention to bring about legal control of narcotics with restriction on their sale and use is contained in a series of statutes. In 1909 Congress adopted a law entitled "An Act to Prohibit the Importation and Use of Opium for Other Than Medicinal 
Purposes." Five years later, in fulfillment of the obligations of the United States under the Hague Convention of 1912, this law was amended to prohibit the export of narcotic drugs except to a country which regulated their entry.

In that same year, in further implementation of the Hague Convention, this country enacted its basic narcotic law, the Harrison Narcotic Act. As an exercise of Federal power to tax, it was enacted as a revenue measure; but by imposing penalties for illegal manufacture and distribution; the effect of its provisions is to regulate the production, manufacture and distribution of narcotics, particularly to limit the availability of narcotic drugs to medical and scientific use. Thus, in an attempt to minimize the spread of narcotic addiction, the Harrison Narcotic Act has been applied as a measure to control the domestic narcotic traffic.

In growing recognition that there was need for a more comprehensive measure of control over import and export of narcotic drugs than was provided by the Act of 1909, as amended in 1914, an extensively revised form of this older statute was re-enacted by Congress in 1922 as the Narcotic Drugs Import and Export Act. It authorized the importation of only such quantities of opium and coca leaves as the then Federal Narcotics Control Board found to be necessary to meet medical needs. With this legitimate exception, importation of any form of narcotic drug was prohibited. Exportation of manufactured narcotic drugs and preparations was permitted under a system of control designed to assure their use for medical purposes only in the country of destination. Under the special amendment to this statute in 1924, the legal manufacture of heroin in the United States ceased.

With evidence of growing abuse of marihuana, the Congress enacted the Marihuana Tax Act of 1937, which requires the registration and payment of a tax by persons who produce, import, manufacture, sell, or transfer marihuana. When growing of the opium poppy, ostensibly for seed yield, sprang up as the result of a shortage of imported poppy seed during World War II, the Congress enacted the Opium Poppy Control Act of 1942, which prohibited the growth of the opium poppy in the United States except under a special license issued only upon a demonstrated need for domestic production of the opium poppy to supply opium derivatives for medical and scientific uses.

Because the Harrison Narcotic Act has been used to exert control over domestic trade in narcotics, its constitutionality has been debated and subjected to test. Although nominally an application of the government's taxing power, the real function of the Act through its provision for penalties for illegal manufacture and distribution has been to restrict the distribution of narcotics to medical and scientific uses only and thereby to attempt to minimize the spread of narcotic 
addiction. Several cases have arisen testing the constitutionality of the Act on the grounds that it is not really a tax measure, but rather an indirect method of invading the police powers of the states; that it undertakes to regulate matters within the exclusive control of the states; and that the penalties amount to a denial of due process of law. The point at issue in test cases on the constitutionality of these statutes has been the extension of indirect control by the Federal government over objects which it is forbidden to regulate directly. The Harrison Narcotic Act has twice been declared constitutional by the Supreme Court, solely as a revenue measure and as an exercise of the Federal power to tax.

\section{ADMinistration}

Originally the Federal Narcotics Control Board had the responsibility of control over narcotic drug imports and exports. The duty of enforcing the Harrison Narcotic Law was assumed by the Bureau of Internal Revenue through its field officers engaged in enforcing all internal revenue laws. There was no separate, specialized group of officers bound exclusively to the duty of enforcing this statute. With a growing realization of the inadequacy of such an arrangement for law enforcement to cope with the control of narcotic drug traffic, the Congress in 1930 established the Bureau of Narcotics in the Treasury Department. To this Bureau were transferred all functions and duties of control over narcotic drug imports and exports and enforcement of the narcotic law which were previously exercised by the Federal Narcotics Control Board and the Bureau of Internal Revenue, respectively. The Federal Narcotics Control Board was thereby abolished. The policy of the new Bureau was to cut off the supply of the illicit drug traffic at the source. Steps were taken to curb the smuggling of large quantities of contraband narcotics. At the same time the Bureau attacked the illicit domestic traffic.

\section{The LaW in ReLation to the Addict}

Among those apprehended in narcotic traffic, whether it be for possession or purveyance, the law recognizes no distinction between addict and non-addict. Judges, however, assert that they distinguish between the addict and the commercial supplier. They regard this distinction as fundamental in the application of penalty. They argue that the laws of penalty should have sufficient latitude to allow judicial discretion for imposing them on an individual basis. But, they complain, Congress has limited judicial power by enacting mandatory penalties.

In actuality, quite apart from the length of the sentence, there are no criteria, no system, no uniformity of practice in the disposition of arraigned addicts. Some are disposed of as criminals, some as sick persons. What happens to the arraigned 
addict seems to be a matter of unpredictable chance, perhaps largely depending upon the attitude and degree of enlightenment of the court.

\section{ThE LAW ON REHABILITATION AND ITS EXECUTION}

Besides its enactment and enforcement of laws designed to limit the trade in narcotics to medical uses and thereby diminish the number of addicts, the Federal government has attempted to provide rehabilitation of the addicts through hospitalization in two Federal institutions. These hospitals in Fort Worth, Texas, and in Lexington, Kentucky, care for 1) those who, on conviction, are sentenced to confinement in such institutions, 2) those who are ordered to submit to such treatment as a condition of probation, and 3) patients who apply voluntarily for treatment. The statute authorizing the Surgeon-General to provide for the "care, protection, treatment, and discipline of" addicts commands: "... Such care and treatment shall be provided at hospitals of the Service especially equipped for the accommodation of such patients and shall be designed to rehabilitate such persons, to restore them to health, and where necessary, to train them to be selfsupporting and self-reliant."

Of interest in the treatment of addicts is the confident and dogmatic pronouncement laid down in the Federal regulations. There it states: "It is well established that the ordinary case of addiction yields to proper treatment, and that addicts will remain permanently cured when drug taking is stopped and they are otherwise physically restored to health and strengthened in will power." In the Federal hospitals the addict is treated as a patient. Actual treatment begins with gradual withdrawal of the drug in order to break the addict's physical dependence on it. An important part of the treatment remains; for the problem contains a large psychological component.

\section{Narcotic Laws and the Private Physician}

Under the law, which was enacted for revenue purposes, the medical and allied professions are charged with the responsibility of prescribing narcotics under restrictions. Physicians may prescribe narcotics to patients for the relief of pain and discomfort associated with disease. They may attempt to treat an addict to free him of this habit, but only in a manner dictated by the Federal regulations. They may not prescribe a narcotic drug to keep comfortable a confirmed addict who refuses withdrawal but who might under regulated dosage lead a useful life and later might agree to withdrawal. These prohibitions are specifically set forth in the Federal regulations:

“... This bureau has never sanctioned or approved the so-called reductive 
ambulatory treatment of addiction, however, for the reason that where the addict controls the dosage he will not be benefitted or cured."

"This bureau cannot under any circumstances sanction the treatment of mere addiction where the drugs are placed in the addict's possession, nor can it sanction the use of narcotics to cover a period in excess of thirty days, when personally administered by the physician to a patient either in a proper institution or unconfined. If a physician, pursuant to the so-called reductive ambulatory treatment, places narcotic drugs in the possession of the addict who is not confined, such action will be regarded as showing lack of good faith in the treatment of addiction and that the drugs were furnished to satisfy the cravings of the addict."

"An order purporting to be a prescription issued to an addict or habitual user of narcotics, not in the course of professional treatment in an attempted cure of the habit, but for the purpose of providing the user with narcotics sufficient to keep him comfortable by maintaining his customary use is not a prescription within the meaning and intent of the act; and the persons filling and receiving drugs under such an order, as well as the person issuing it, will be regarded as guilty of violation of the law."

It should be added that a verdict of guilty carries a prison sentence. All things considered it is small wonder that most physicians would prefer not to have addicts appear as patients in their offices.

Here is an instance where it would seem that control of medical practice has already come under Federal power. However incongruous it may seem, the government has achieved that control indirectly through a revenue measure.

It has been seen that the Federal government has attempted to minimize the spread of narcotic addiction through restrictions on the sale and use of narcotics and through suppressing illicit traffic in narcotics both internationally and domestically. It has exercised control over export and import of narcotics; particularly it has aimed to cut off illicit supply at its source and to curb smuggling. It has also exercised control over domestic traffic by regulating production, manufacture and distribution of narcotics. It has restricted the drug to medical and scientific use. Violations of the narcotic laws carry penalties. Under these laws the government has attempted to apprehend and sentence those engaged in illicit traffic. As has been noted, it achieves its objective indirectly.

These Federal regulations embody a philosophy of approach to the problem of drug addiction. First, it reflects the view that it is possible to stop the spread of drug addiction by prohibition of the drug. Deprivation of the drug is to be accomplished by stopping supply. Secondly, it reflects a punitive approach in 
that stiff penalties are to act as a deterrent. Thirdly, by virtue of possession or of selling the drugs, the drug addict is regarded as a criminal. Among violators of the narcotic laws no distinction is drawn between addicts and non-addicts. Fourthly, it exercises rigid control over the physician in the practice of medicine. It makes the physician responsible for administration of the drug; but it sets down medical opinions on prognosis and dictates the kind of treatment in statutes. The Harrison Act itself did not attempt to deal with the problems of the addict; it attempted only to regulate the flow of narcotic drugs. The interpretations of the Act, however, have altered what appears to have been the original intent of the measure in such a way that it is now difficult for physicians to render medical care to narcotic addicts except under carefully prescribed circumstances.

\section{THE EXISTING SITUATION}

How effective has been this approach? Here we are actually concerned with its bearing upon two separate but interrelated components: traffic in narcotics and the drug addict. The latter in turn has two divisions: the formation of new addicts and the rehabilitation of existing addicts. First to be considered are narcotic traffic and the spread of addiction. Has there been diminution in the volume of traffic and spread of addiction? Is there proportionately more or less traffic and addiction prevalent? What is the existing situation?

\section{Prevalence of addiction and illicit Traffic}

There are assertions that there is an increased prevalence of drug addiction. If so, it may be inferred that there is an increase in drug traffic. But not all authorities accept this assertion. There are counter-claims that drug addiction under present regulations has diminished. The uncertainty grows out of a lack of substantiated and convincing statistics. There is no accurate information obtainable on the number of addicts in the country. Data on the number of arrests for violation of the narcotic laws do not give information on the number of undetected addicts in the nation; only those who come into contact with the law are now available for counting and even those do not provide an accurate measure of the prevalence of addiction because their arrests are too often recorded under other charges. A careful medical evaluation of those arrested as "thieves" would probably show that in a number of instances they should more properly have been classified as "addicts."

Inasmuch as the addicts are classed and hounded as criminals it is just about as difficult to take a census of them as of burglars. Indeed, because of the nature of their violation it is more difficult, because burglaries, if not burglars, can be counted. Certainly it is not to be expected that drug addicts as presently perse- 
cuted are voluntarily going to step forth to be counted. Under our present statutes the addict makes every effort to avoid being among those counted in the statistics of the police and courts. Inasmuch as the present attitudes toward addicts are punitive rather than helpful and understanding, they have no desire to come into contact with those who will do no more than assure that they will no longer have access to their drug supply. So there is an abundance of estimates and opinions and a scarcity of hard facts. In the face of admittedly incomplete information it assuredly requires considerable boldness to maintain that drug addiction is on the wane. Indeed, according to an article in the press a few days ago, it was estimated by the Bureau of Narcotics that the proportion of addicts in the American population today is 31/2 times what it was between 1938 and 1948.

What is more, there are strong indications that there has been a change in the type of addict which creates a situation that is even more sinister and ominous. Twenty years ago addicts were generally adults in the latter part of their life span; today addicts are predominantly under 30 , not infrequently youths. A lifetime of addiction potentially lies ahead of them. The number of these young addicts multiplied by their life expectancy gives a numerical product that reveals today a situation of such magnitude that it far transcends that of two decades ago. Inasmuch as a considerable portion of these young addicts become "pushers," what with their long life expectancy in addiction, they have a correspondingly long period to engage in recruiting. The net effect is almost certain to be more vicious than an increased number of older addicts who can afford their habit.

Engaged in drug traffic are four grades of sellers:

1. The importer, rarely an addict, who "supervises" the smuggling of drugs by his employees and who arranges for their distribution to the wholesale outlet.

2. The professional wholesaler, also rarely an addict, who obtains his supply from a larger wholesaler or the importer, and who seldom has any contact with addicts.

3. The "peddler" who may be, but is not always, an addict, who sells directly to the "pusher" addicts in small amounts the supply he obtains from the wholesaler.

4. The "pusher," an addict who sells narcotic drugs to other addicts in order to obtain funds with which to purchase his own supply. By and large, the "pusher" does not deal in drugs in quantity. He is concerned with selling them to other addicts only in order to maintain his own supply, not to make a profit beyond his own financial needs.

This organization is sometimes called a drug ring.

For fundamentally the same reason, money, both the importer at the top and many "pusher" addicts are engaged in spreading addiction. But there the 
similarity ceases. For the importer's quest for money is to satisfy a desire for it in large quantities, which is potentially obtainable because of the big profits. For drug traffic is primarily an operation in economics. The narcotic laws shut off any legitimate source of drugs for a market with an uncontrollable craving. The stage is set for inflation with profits of such enormity as to strain the imagination. Prohibition of narcotics creates a situation in which traffic to supply the demand for a product legally unobtainable is highly hazardous but just as highly profitable. Because of the profit to be made in selling illicit drugs, attempts are made to attract new users. Drug rings constitute big business with all its aggressiveness to increase volume of sales. And what is more, a large part of the sales force are compulsive consumers of their own product without even a house discount.

The addict's search for money, unlike that of the importer, is to satisfy first and foremost a craving for drugs. In this respect the drug traffic has also undergone a change, largely in the kind of salesmen and customers. Previously the addict came to drugs in search of relief from pain, fatigue, or anxiety. He had his source of supply and the means to gratify his craving. He did not recruit new addicts. But today the young addict, with insufficient funds, is driven to "pushing" and creating new addicts in order to obtain a supply for his own needs.

Whereas the importer searches for new customers in order to increase the volume of sales because of the enormous profit to be gained, the "pusher" seeks new customers in order to increase his earnings so that he may be able to purchase the drug for which he has a craving that must be satisfied. His efforts to make new addicts may not even be voluntary. Sometimes, in order to maintain his habit, the addict who is a "pusher" is coerced into persuading non-users to try drugs in the hope that they will be "hooked" and become steady customers. From the standpoint of the importer, promotion of drugs and their greater acceptance among youth with the prospect of a life-time of repeat sales in this special consuming group, is a highly satisfactory and desirable enterprise. On the other hand, just as the young addict has potentially a longer span of addiction ahead of him, so he has a longer span of participating in drug traffic. So addiction and drug traffic increase each other successively in a vicious spiral.

If one were to rate the four levels of participants in drug traffic in terms of criminality and danger to society, the importer would rank first; the wholesaler, second; the peddler, third; and the "pusher," fourth. The most reprehensible of the drug suppliers is the one farthest removed from the drug users. The importers and wholesalers are clever criminals with great financial resources. They are most difficult to apprehend. To obtain their conviction requires careful preparation of their cases and ironclad evidence of law breaking. All this is a nearly impossible 
task. Certainly the hard-working staff presently attempting the impossible should not be criticized for not accomplishing it. Nor is there any strong reason to believe that a larger force would completely abolish illicit drug traffic. Indeed, the Commissioner of the Bureau of Narcotics was quoted in the press a few days ago as testifying that, "if you had the Army, the Navy, the Coast Guard, the F.B.I., the Customs Service and our [narcotics] service, you would not stop heroin coming through the Port of New York."

To combat and prevent addiction, the law depends on stiff penalties. The hazard of engaging in drug traffic is great because the penalty is high. But for the non-addict importer and wholesaler, the profits are correspondingly high. For the addict who "pushes" or peddles, the penalty and hazard are also great; but so is his craving for the drug. Indeed, the addict has so great a craving that he becomes determined to get the drug without counting the risk.

It has been noted that two types are engaged in drug traffic: the addict and the non-addict. The existing body of law does not draw a distinction between them in the application of penalties. To impose the severe penalties upon an addict who sells to other addicts or, out of fear, to non-addicts, is desirable. Narcotic addicts should be considered sick persons and should not be penalized for activities which stem primarily from their ill-conceived attempts to alleviate their own suffering. As for those persons who are not drug addicts but who are interested only in their own personal gain without regard to the suffering and misery their commerce may cause, to impose severe penalties upon them is not only eminently just but highly desirable.

\section{Drug Addiction and Crime}

Drug addicts fall into the toils of the law in two ways: they are arrested for possession or sale of narcotics; or for hold-ups, housebreaking, breaking into cars, shoplifting, prostitution, mugging, purse snatching, pickpocketry. Obviously their object in perpetrating these crimes is to obtain funds to meet their needs. Since drug addiction is characterized by a craving transcending all other appetites and since it is an extremely expensive habit, it may be presumed that it is the most pressing, though not necessarily the only, reason that the addict commits crime. Certainly a large volume of crime is associated with drug addiction. At present it is debated whether crime is a consequence or an antecedent of drug addiction. Perhaps both are true. There is not sufficient evidence to permit the ready conclusion that drug addiction is responsible for a large part or most of the crimes in the category of theft and larceny. It would be equally untrue to assert that all addicts, in addition to their violation of the narcotic laws, 
have criminal records. But it would not be beyond the realm of fair speculation to suggest that in a proportion of addicts the economics of their addiction led them to start or continue in crime.

\section{REHABILITATION}

Next to be considered is the record of success in attempted rehabilitation. Most of the treatment of addiction is conducted in the two Federal hospitals especially administered for that purpose. Although the private physician is allowed under the law to cure addicts if he follows the mode of treatment prescribed in the Federal regulations, for reasons which have already been brought out, as well as the difficulties inherent in attempting it on an outpatient basis, he seldom undertakes it. In the hospital actual treatment begins with gradual withdrawal of the drug. Failure of the jail system for addicts has proved useful in one respect. It shows conclusively that mere abstinence from narcotics for long periods of time does not cure addiction. A constructive approach to treatment must be based on something more than a mere separation from the drug supply. There is a large psychological element in drug addiction; hence measures to rectify it are a major part of the therapy.

When attempts are made to appraise the success of the therapeutic efforts, two difficulties are encountered: 1) obtaining reliable data; 2) setting standards. It is difficult to do any follow-up study on those addicts who are discharged from institutions providing treatment for them; for there is presently no way of keeping track of them other than by their voluntary communications. Hence, the records leave much to be desired as a basis for determining the period of time prior to relapse, whether the "cured" addict abstains from drugs one day, one month, one year or for life.

Even if the data were more reliable, it is disappointing, if not misleading, to apply the older and more conventional criterion; namely, the percentage of cures. One source reports that on the basis of five-year follow-ups the results at the U.S. Public Health Service Hospital in Lexington, Kentucky, were 20 per cent known abstinence; 35 per cent known relapse; 40 per cent not heard from or never contacted. It is pointed out that of the 40 per cent on whom data were not obtained, a considerable number may have continued to abstain since no hospital or police record of them could be found. Considering the success of treatment for drug addiction as a whole, another source states that: "Probably less than $50 \%$ of treated drug addicts remain free of their habit."

But addiction is not like a communicable disease in which one attack and subsequent recovery confers immunity for life. Actually it has a large psychologi- 
cal as well as physical component. Furthermore, it is related to so many characteristics of man that success in treatment is better expressed in a more relative term than "cure.' Addicts do not constitute a homogeneous group. They vary in age, personality, constitution, environmental background, culture, their mode of becoming addicts, and the duration of their addiction, to name only a few points of difference. Several broad groupings may be recognized. But to speak of the aggregate of addicts as a group, it must be borne in mind that the only thing they have in common is their addiction. These variables are reflected in the record of the effect of rehabilitative measures. In addition, the present state of knowledge on effective rehabilitation must be taken into account. Under these circumstances, it is misleading to speak of cures and to set a standard of freedom of addiction for the rest of the patient's life following an adequate period of therapy.

When effects of two years' therapy are judged by the length of abstinence before relapse the latest data show a wide range, with a small percentage having a long term abstinence. But successive subjection of relapsers to a regimen of rehabilitation brings each time a small but definite percentage of long term abstinence.

The explanation of these results is not entirely clear. There is very inadequate follow-up of discharged patients which assuredly must shorten the record of abstinences. Also of course the present medical approach to rehabilitation of the addict represents almost a first attempt with admittedly incomplete knowledge. Much remains to be learned about drug addiction and its causes which in turn will shed further light on treatment of it.

Examination of the record of success in rehabilitation is important for the light that it may shed on the biology of addiction and on the quality and quantity of rehabilitative efforts. Valid conclusions drawn from reliable data assist in answering significant questions about the biology of addiction and particularly its responsiveness to treatment. Does rehabilitation necessitate a simple or complex procedure? Is it a short or long process? Is the improvement temporary or permanent? From all available evidence it may be said with some confidence that addiction is a complex disease and may therefore require a complex therapeutic approach. Certainly with the presently available methods rehabilitation is a relatively long process. With a successive series of therapeutic courses the results show increasing improvement.

The answers to these questions are important in order to make policy and decisions on the approach to control of narcotic addiction. It may be fairly said that in the present state of knowledge rehabilitation does not offer a quick means 
to help stamp out existing addiction and prevent new recruits. But rehabilitation is an essential part of any program in controlling drug addiction. The urgent need is for additional knowledge and wider application.

In considering the quality and quantity of existing Federal rehabilitative services the following questions may properly be asked: Insofar as resources permit, is everything being done that should be done and is it being done well? Should the Federal institutions for rehabilitation of the drug addict be continued? Could these institutions do even more effective work with additional resources? Within the limitations of existing knowledge and their resources, it is our opinion that the quality of their services is beyond reproach. It is our belief, however, that there is insufficient use of these Federal institutions and that many more addicts should be undergoing treatment. This is of course a situation over which the institutions themselves have no control. Rather it points to inadequacies in the system of referrals or funds, or both.

In a sense the question whether the Federal institutions for the treatment of addicts should be continued is rhetorical. It is beyond dispute that there are existing addicts. This is cold reality, not an indefinite possibility. What is society going to do with or for them? Perhaps the most difficult part of the vast problem of drug addiction is the proposal of constructive steps for the care, supervision, and treatment of the existing addict.

There is valid reason to believe that these institutions could produce even more effective results in rehabilitation with additional resources. Under the present system, rehabilitation ceases before it is finished. The addict, following his stay at the institution, is given carfare to his home and a warm farewell; then he is dumped as a solitary figure, penniless, very often friendless and without work, in a hostile society. It would test the mettle of a healthy man to undergo this experience; it must be a real trial to the discharged addict. Here is a gap that needs to be filled.

\section{CONCLUSIONS ON THE EXISTING SITUATION}

From this appraisal of developments under the present punitive approach to the problem of drug addiction, it is the Academy's belief that the following conclusions are justified:

The illicit drug traffic still persists and it prevails in an even more sinister form since it now enslaves many youths.

Twenty-five years of the present laws have not accomplished to an unequivocal extent: suppression of illicit drug traffic; prevention of the spread of drug addiction. 
The punitive approach is no deterrent to the non-addict dealer or to the addict. The threat of stiff penalties in the form of jail sentences has not prevented the non-addict dealer or the addict from taking the risk. Furthermore, the serving of sentences in jail has not proved the solution of drug addiction. For one thing, the record of repeat jail sentences for addicts is so large that the procedure has been called "the revolving door policy." For another, confinement in jails succeeds in thoroughly instructing in the ways of the underworld those addicts who had not yet engaged in criminal activity. Particularly in the case of young addicts the jail sentence is a dangerous approach to a medical problem. During incarceration the young addict, who had perhaps not even finished school because of his subjection to narcotics, learns from other prisoners not a skill with which he can support himself, but how to get along without working at all, even less desirable ways of maintaining his drug habit, and a complete course in drug addiction. It has been demonstrated that a jail sentence does nothing to help the addict recover from his addiction.

In view of the enormously magnified economic aspects of drug traffic, perhaps the punitive approach may not be the most effective way to bring about substantial reduction in drug addiction.

Under the law, most of the addicts are regarded as criminals rather than sick persons.

The present Federal regulations control the practice of medicine in relation to drug addiction to such an extent, and so look upon the physician as a potential criminal, that he prefers not to include the treatment of drug addiction in his practice.

Drug addiction is a more serious and difficult social and medical problem when it affects youths than older persons.

Judged by the criteria of abstinence from narcotics and, of accession to a gainful occupation in society, the rehabilitation of the drug addict in our present state of knowledge is a highly expensive, exceedingly slow and prolonged procedure necessitating repetitive efforts.

As a means of stamping out drug addiction, prevention remains the most practical and essential step. The crux of any program aimed to rid society of drug addiction is to stop the formation of new addicts.

The program of the past has also been inadequate in two approaches which hold promise of contributing to the diminution of drug addiction: research and education.

The Payne Bill proposed amendments to the various narcotic laws bearing upon several aspects of the problem. Briefly stated, it would have transferred 
the Bureau of Narcotics from the Treasury Department to the Department of Justice; it would have expanded facilities for the care and rehabilitation of drug addicts; it would have instituted an education program in teacher training colleges; and it would have applied stiffer penalties for violation of the narcotic laws.

The proposed transfer of the Bureau of Narcotics from the Treasury Department to the Department of Justice was in accord with the recommendations of the Hoover Commission.

Contained in the preamble of the bill was this statement: ". . the need continues and grows for reduction of the demand for such [narcotic] drugs through proper treatment, cure, and rehabilitation of persons already addicted to the use of narcotics." In accordance with this view, the Payne Bill proposed to provide suitable care and rehabilitation centers for those who were addicted to the use of narcotic drugs. Such treatment was to be under the jurisdiction of the Department of Health, Education and Welfare and included provisions of assistance to states establishing rehabilitation facilities as well as for the training of personnel to serve in such institutions.

The bill also proposed to encourage the establishment of training centers for teachers and in part to subsidize the compensation of instructors for such courses. Thus it provided for teachers and teacher training programs. Recognition of the need to train teachers to give narcotic education is also evidence that an adult education program would be desirable. These are healthy efforts toward prevention, especially in a long-range program. But they should not be expected to bring prophylactic results at once.

The Payne Bill continued the punitive approach with even stiffer penalties. For example, "Whoever sells, transfers, barters, exchanges, or gives away, or facilitates the sale, transfer, barter, exchange, or giving away, of any narcotic drug ... to any person who has not attained the age of twenty-one years, shall, notwithstanding any other penalties provided by law, be punished by imprisonment for twenty years. For a second offense, ... the offender shall suffer death, unless the jury qualifies its verdict by adding thereto 'without capital punishment', in which event he shall be sentenced to imprisonment for life." The giving of drugs without cost is presumed to take place in "hooking" a new addict. Both parties are frequently under twenty-one. The penalties of twenty years' imprisonment for the first offense and execution for the second, when applied to youths, seem slightly severe.

Furthermore, in inflicting extreme penalties for trafficking in illicit drugs, the proposed bill failed to recognize that narcotic addicts, even though engaging in 
activities designated by it as illegal, are first of all sick persons and only incidentally law breakers. At the very least, the measure should have provided for a careful review of each case by a competent medical board, to assure that the sale of narcotic drugs by an addict was not being perpetrated for profit alone.

The preamble of the bill stated that "strongly deterrent penal laws, with alert enforcement, are acknowledged to be the most effective method of terminating illicit traffic and supply of narcotic drugs for profit." The soundness and accuracy of this theory is open to question in practice. The spectre of the noble experiment in alcohol still hangs over us. Severe penalties apparently mean little or nothing when measured against potential profits or inner craving. The death penalty for addicts is said not to have stopped addiction in China.

The Academy's principal objections to the Payne Bill are its punitive approach and excessive penalties. In its opinion, the bill would have been no more successful in stamping out addiction than the present laws which it would have amended. Indeed it might have brought an even greater degree of failure to the extent that its penalties were unreasonably excessive.

In short, the Payne Bill contained several commendable provisions, but these were more than offset by its continued punitive approach with fantastically severe penalties.

\section{THE ACADEMY'S PROPOSALS}

The objective is to stamp out drug addiction as completely as possible. The crux of this objective is to diminish the number of individuals becoming newly addicted. The natural decrease with time in the number of existing addicts must not be overbalanced by the formation of new addicts at a more rapid rate. Indeed, if the objective of little or no addiction is to be achieved, there must be little or no formation of new addicts. Furthermore, whatever the policy adopted to abolish new addiction, there still remains the responsibility for those presently addicted. Concurrently with the attempt to stop the formation of new addicts, efforts should be directed to rehabilitate as many presently addicted persons as is possible. As a second objective such efforts would not only reduce the prevalence but would also contribute to stopping the spread of addiction. Finally, medical supervision should be provided for individuals already addicted to narcotic drugs who are resistant to rehabilitation.

The Academy proposes a six-point program to achieve these objectives. It should be emphasized that all measures are to be instituted, not just one.

1. There should be a change in attitude toward the addict. He is a sick person, not a criminal. That he may commit criminal acts to maintain his drug supply 
is recognized; but it is unjust to consider him criminal simply because he uses narcotic drugs.

2. The Academy believes that the most effective way to eradicate drug addiction is to take the profit out of the illicit drug traffic. The causes of addiction are cited as: maladjustment; underprivilege; broken home; poverty. Such conditions may well be contributory factors, but they are not of themselves the prime cause. Rather, profit looms large as the principal factor.

In seeking ways to reduce the formation of new addicts, it is helpful to consider the mechanisms of addiction and its spread. Availability of the drug, ignorance, curiosity and persuasion are the necessary ingredients for initiating drug use. Curiosity and the need to conform to the behavioral code of his age-group is probably a factor in attracting an adolescent to the use of narcotic drugs. In this group, it is common practice to designate a none-user as "chicken" or as "a square" if he refuses to use drugs. For certain individuals the ridicule of his fellows is unbearable; even though not wishing to do so, he finds himself taking drugs and, ultimately an addict.

Prospective users are furnished drugs by the "pusher" until addiction occurs. But once this has taken place, the addict is required to pay for every dose and thus a life of slavery begins. Therefore, the formation of new addicts is principally the result of commercial exploitation. Contained in the preamble of the Payne Bill is the assertion: "Illicit traffic in arcotic drugs for profit are the primary and sustaining sources of addiction. ... [sic]" If all profit were removed from dealings in narcotic drugs, there would be no incentive in giving away these drugs in an attempt to addict others.

The addict should be able to obtain his drugs at low cost under Federal control, in conjunction with efforts to have him undergo withdrawal. Under this plan, these addicts, as sick persons, would apply for medical care and supervision. Criminal acts would no longer be necessary in order to obtain a supply of drugs and there would be no incentive to create new addicts. Agents and black markets would disappear from lack of patronage. Since about eighty-five per cent of the "pushers" on the streets are said to be addicts, they would be glad to forego this dangerous occupation if they were furnished with their needed drug. Thus the bulk of the traffic would substantially disappear. By its very nature this traffic requires many agents scattered in diffuse neighborhoods. If a few unaddicted "pushers" were all that remained to carry on the trade, they would present a lesser problem for apprehension by the police.

3. An integral part of the program would be medical supervision of existing addicts, with vigorous efforts toward their rehabilitation. No particular philoso- 
phy of stamping out drug addiction and traffic has an exclusive proprietary of rehabilitation. Whatever the method it must include a plan and operation to rehabilitate the existing addict. This objective carries three parts: 1) persuasion of the addict to undergo treatment and rehabilitation; 2) appraisal of the methods of treatment and their success; 3 ) supervision of addicts who were resistant to undergoing treatment or refractory to treatment.

By a change in social attitude which would regard them as sick persons, and by relieving them of the economic oppression of attempting to obtain their supply of drug at an exorbitant price, it will be possible to reach existing addicts in an orderly dignified way, not as probationed persons or sentenced criminals. They would come under supervision in the interest of health, not because of entanglement with the law. Thereafter, on a larger scale and in a humanitarian atmosphere, there would be opportunity to apply persuasion to undergo rehabilitation. It is reasonable to expect that more might accept the opportunity.

It is a temptation to think of addicts as a homogenous group, whereas all that they have in common is their addiction. They differ in age, personality, constitution, social and cultural environment, and length of time of addiction. Each addict is therefore an individual therapeutic problem. Present methods to convert addicts into abstainers have comprised removal of the drug and then institution of rehabilitative measures. Physical dependence on drugs can be removed by the withdrawal treatment. The mental and emotional fixations, however, are to be overcome only through the individual's own efforts and desires. Psychotherapy cannot be forced upon him with any hope of lasting benefit. Rehabilitation of severely addicted individuals to the point where they abstain from drugs for the remainder of their lives has been shown to be an extremely slow process with an equally slow rate of success. The present therapeutic regimen has suffered from premature termination of support to the patient. There is a need to maintain continuing contact with recovered addicts so that they may be helped in resisting the return to use of a drug in stress situations. A counselling service for them is urgently needed.

Not all the addicts subscribing to the proposed plan will agree at once to undergo treatment. In accord with this concept that treatment of the addict must be individualistic, the Academy believes that in appropriate institutions it might be well to try a reverse order. After the addict has undergone education and rehabilitation and has obtained employment, there might be more success in inducing him to give up the drug. It has been asserted that many addicted individuals become enslaved between the ages of seventeen and twenty. It is evident that addiction then occurs before the individual has had an opportunity 
to acquire a skill by which he can earn an honest living. If he is furnished his drug in required amount, he may be willing to be trained in a useful trade. When he has been enabled to maintain his livelihood with his former fears and stains removed, he may be willing to give up drugs. Thus a change in social attitude and a different therapeutic approach in appropriate instances might offer more success in persuading an addict to undergo treatment and in the results of that treatment.

Addicts resistant to undertaking therapy and continuously refractory to therapy, despite all efforts, should be supplied legally and cheaply with the minimum amount of their drug needs; and efforts to persuade them to undergo rehabilitation should be continued.

It is suggested therefore that there be developed a program whereby sufficient amounts of drugs can be legally and inexpensively supplied to addicts, while attempts are being made to have them undergo treatment. This service for narcotic addicts should be instituted in dispensary-clinics, preferably attached to hospitals, whether Federal, municipal or voluntary. No person should be given drugs at such a service clinic unless he is willing to enter a hospital for evaluation of his drug needs. After careful medical evaluation he should receive at cost from the service clinic the amount of drug which it has been medically determined that he requires.

The service clinic should be in operation twenty-four hours a day, seven days a week, to insure that no addict has the excuse that he could not obtain his supply from a legitimate source and was thus forced by his discomfort to seek his supply from illicit dispensers. At no time should he be given a supply of narcotics adequate for more than two days; if he is found to have sold or given away any of the supply to another person, he shall be liable to commitment to a hospital with attempted rehabilitation.

If an addict uses more than the amount of drug supplied to him for the prescribed period, he should not be penalized so long as he returns to the service clinic for his legitimate supply. But in the event of such a lapse from the pattern of his consumption of drugs, he should be re-admitted to the hospital for another evaluation of his drug needs.

Needless to say, all addicts receiving drugs from the service clinic or entering a hospital for evaluation and treatment should be photographed and fingerprinted; copies of such photographs and fingerprints should be sent to a central agency, while one copy is retained at the original clinic. By means of a punchcard system, monthly checks should be made by the central agency to insure that an addict is not obtaining supplies from more than one clinic. If such a violation is found 
to exist, the offending addict shall immediately be subject to commitment as a hospital patient.

It is visualized that such service clinics will be established all over the country. Thus it will be possible for an addict desiring to change his residence to transfer from one service clinic to another without encountering difficulties in maintaining his supply. Whenever an addict wishes to go to another community, he will notify his regular clinic of his intent. The clinic will in turn notify the central agency of his new location and will forward to the new clinic the record of his evaluation and his conduct at the original clinic.

Strictly enforced, these safeguards should eliminate any possibility of the use of the illicit market and should insure that only those with intractable addiction are actually receiving narcotics. It is also postulated that there will be no laxity in enforcing provisions for failure to abide by the service clinic regulations.

Much space, perhaps a disproportionate amount, has been devoted to detailing the provisions for furnishing drugs to the addicts who refuse treatment. Actually it is hoped that this group will be small in number and constantly diminishing. For, all the while, unrelenting attempts would be made to persuade the resistant addict to undergo therapy to break the habit.

It will be seen that this recommendation is a humane, reasonable, and promisingly effective method of distribution. It should be remembered that every addict will get his drug. Under the present laws to do that he must "push," rob, steal, burglarize or commit forgery. For, he is desperate when he is without drugs.

This part of the program containing provision for distribution of drugs to addicts has been opposed on the basis of previous short-lived experience with drug clinics. Admittedly some of the clinics were abused; others had success. In any event, there was insufficient time for them to demonstrate their merits. There is an aura of mystery surrounding the peremptory and premature closing of them. From all available facts it would appear that they were closed, not because they had failed, but because operation of them did not accord with the prevailing philosophy of a punitive approach to a criminal problem.

4. It is proposed that there be no relaxation in the efforts toward complete and permanent elimination of the supply of illegal narcotic drugs and that provisions for suppression of illegal traffic be retained. It is the Academy's belief that the suggested plan to remove the profit would diminish illicit traffic. Whatever illicit operations were left after its application should be vigorously eradicated by appropriate laws, their enforcement, and provision for suitable penalties. Here illicit traffic should be re-defined to allow provision of drugs to addicts under medical supervision and treatment. This procedure should be 
surrounded by suitable safeguards. If anyone receiving drugs under the supportive plan should be found attempting to receive or to be receiving supplies from more than one clinic or from an illicit market, or if he be found attempting to sell or actually selling any of his supply to another person, he should be liable to commitment to a hospital with attempted rehabilitation. Thus he should be controlled as a sick person, not as a criminal.

Initially, it would be essential to provide the trained staff necessary to apprehend the peddlers, wholesalers and importers. It goes without saying that this group will not give up its lucrative business without a struggle. But a dearth of drug users, combined with severe penalties for dealing in narcotics, could be expected to put an end to the illicit drug traffic within a relatively short time.

It should be emphasized that the law should draw a distinction between the addict and non-addict in its provision. The convicted non-addict trafficker should feel its full force.

5. Adolescent addicts are reported to have said that they would not have taken drugs in the first place if they had known that they were going to become addicted. Such statements of youth are a strong argument for a good educational program for young people. The adult user, too, reports that he did not know the dangers of narcotic drugs when he began their use. If such reports are correct, it would appear that an educational program for adults as well as for adolescents is needed.

Combined with the medical care of narcotic addicts and severe penalties for trafficking in drugs, there should be an adequate program of education for adults, teachers and youth. By means of all education media, including radio, television, the public press, forum, lecture, books and pamphlets, there should be a concerted effort at informing the public of the dangers of narcotic drugs. Furthermore, there should be impressed upon the population the need to treat addicts, to apprehend illicit drug dealers, and to avoid the use of such drugs except under medical supervision.

6. One of the great difficulties in planning for a medical approach in the care and supervision of addicts is the lack of accurate information on their number. So long as they are stamped as criminals that difficulty will exist. It is a merit of the medical approach that by adopting the proper attitude toward them, it should be possible to study the epidemiology of drug addiction and acquire information about the magnitude and pathogenesis of the disease.

By means of the records accumulated at the central agency, it would be possible to have at all times an accurate count of the known resistant addicts in the country. It would also be possible to know how many addicts were undergo- 
ing treatment for their illness and how many relapsed after a period of abstinence. Data on the length of abstinence from narcotic drugs and therefore on the success of various types of treatment would be obtainable. On the basis of such information, research could be focused more readily on the "why" of addiction and on improved methods of treatment. There seems little possibility of learning the "why" of addiction until narcotic addicts can be studied under conditions more nearly approximating normal existence than do those of a hospital, excellent though it may be.

So much has been stated about the relation of drug addiction and crime, particularly about the need for drugs leading to crime, that the Academy is moved to state that realistically it has no extravagant expectations that the proposed plan will completely eliminate crime. If a person was a criminal before he became a drug addict, it is not necessarily to be expected that he will cease to follow his predilections for crime just because he no longer is an addict. Perhaps it is fair to state that crime arising from the need for drugs may diminish; but criminal acts committed for other reasons may not decrease.

It is the opinion of the Academy that this program, taken in its entirety, is a reasonable and humane approach to the solution of drug addiction. It must be frankly admitted that there is no ideal or perfect solution. Of the two possible approaches to the solution of the problem, the punitive as against the medical, it becomes a matter of judgment as to which gives the more promise of effectiveness and contains fewer points of vulnerability. In judging between them the Academy believes that the evidence is preponderantly in favor of its proposed program as the more promising means of ridding the nation of drug addiction. 